that our technologists will be able to continue to devise machines at the present rate of development, and perhaps, at an accelerated rate; secondly, that the capital will be available and that the machine tool industry will be capable of producing them; that the people of the world will be able to produce and to exchange the raw materials required for these machines, and by these machines. Thirdly, that there is going to be a demand for the products of these machines, and that the spending power to acquire thom will be available. Fourthly, that good relations between workers and management are achieved-relations of such harmony that vast industrial disturbances become entirely old-fashioned. Lastly, that the benefits of this new age will spread throughout the world.

First, however, man must adapt his industrial customs and his outlook to what many people call the new machine age. Secondly, the use to which man will put the rewards of these technological changes must be considered.

The problem of the redeployment of the labour force is the widespread conviction that, unless something is done, the social and the economic cost of industrial change is going to fall upon the individual worker.

What is noeded is a new recognition of social responsibility in industry at the level of the individual firm and the application of that responsibility over a long period. The real responsibility for planning must lie at the level of the individual firm. Employers must now accept the moral responsibility for planning the employment of their work-people exactly in the same way as they accept the management responsibility for planning the building of their factories, the installation of machinery as well as development of their markets.

This is not just a matter of paying monetary compensation; it involves a much deeper change of attitudes, and of habits, which can only come about if everyone in industry is ready to face the full significance of technological change.
Industry can also make a contribution to the problem of adapting society to technological change, and that is in the field of training. The main responsibility of training in industry is industry's itself. If industry paid more attention than it does to the establishment of effective schemes of training for new entrants, it would not only save money for itself but it would also make a most valuable contribution to the flexibility and the increased mobility of the labour force that is so essential to the British economy.

For many years there has been a trend towards the breaking down of processes and, therefore, the training of workers on one operation only. There may be a reversal of that process, a tendency towards synthesis and a training of workers to understand any one in a whole chain of operations ; if this is so, it will make greater demands on the capacity of workers, and training for new kinds of work will require a new approach.

What about the rewards from technological change? The expectation is that the new era of production will make possible a higher standard of living. It should remove some of the drudgery and the physical exertion that is still existent in industry. It may be that it will bring more leisure, which in itself will bring a problem with it. If leisure is wrongly used it is bound to lead to boredom and to discontent which will sap and rot our civilization.

Other features of the Conference were a series of one-day courses dealing with the training of operatives, industrial pension schemes, selection methods, and the part of work-study in retail staff management. There were also a number of sectional meetings where delegates were given opportunity to consider details of recent developments in the training of managers, to discuss the case for and against the payment by results, to examine new suggestions which could be used as bases for pay differentials, to explore communications within the work force, and to learn of recent developments in the mechanization of office work.

\title{
PHYSICAL CHEMISTRY OF PROCESSES AT HIGH PRESSURES
}

\begin{abstract}
A
TWO-DAY discussion meeting of the Faraday Society on the generul theme of "The Physical Chemistry of Processes at High Pressures" was held in the Chemistry Department of the University of Glasgow during September 20-21. Some 162 British and 58 overseas scientists attended the meeting, and a lively and well-sustained discussion resulted. Many of those present had the opportunity of enjoying a display of Scottish dances and Scottish songs, through the kind hospitality of Imperial Chemical Industries, Ltd.

This was the first Faraday diseussion with this general theme ; it is evident that for condensed states of matter, the pressure variable has been much less fully explored than the temperature variable. However, high-pressure techniques are becoming easier to develop and to apply, at any rate up to about 5,000 atm. Increased accessibility of operations at high pressures has resulted in a broadening of the range of physico-chemical measurements becoming available for interpretation. For still higher static pressures, equipment is at present too specialized and costly to
\end{abstract}

favour its widespread dissemination in many labora. tories ; but results important for the thermodynamics of condensed phases are being obtained in a few centres. The use of transient high pressures up to $10^{5}$ atmospheres or more, as developed in shock and detonation waves in solids, was first applied to the measurement of thermodynamic parameters during the Second World War. Increased attention is being paid to the development of such techniques at the present time, though there are still serious difficulties of interpretation, particularly in systems containing a mixture of solids.

Industrial interest in high pressures has received obvious stimulus from the highly successful polymerization of ethylene and the suggestive results in the polymerization of acetylene, and adds to the significance and timeliness of the recent discussion.

The papers presented and the discussion make it clear that systematic theory has not wholly kept pace with present experimental developments, though some of the contributions at this meeting clarified important theoretical problems. The influence of 
repulsive forces in practically all high-pressure phenomena is widespread. A useful survey by Dr. 'T. Cottrell (I.C.I., Ltd., Nobel Division) brought out the difficulties in finding high-pressure parameters that are at the same time simple to calculate theoretically and experimentally sensitive to repulsive forcefields. Various contributors discussed the form and characteristics of repulsion potentials. For close molecular overlap a simple inverse power function of molecular separations fails to represent repulsions successfully; an exponential function may be more hopeful, though a composite function with more than one adjustable parameter seems to be roquired if the range of repulsion potentials under discussion is at all large. The anisotropy of repulsive force fields for non-spherical systems, and additional complications where repulsions arise in a many-body problem present othor obstacles to theoretical progress. From the discussion it was evident that some of the difficulties are only just beginning to emerge clearly. One promise of theoretical advances stems fron the much greater diversity of experimental phenomena, where measurements are becoming available from which repulsive force-fields might in principle be calculated. This was illustrated by many of the experimental contributions to this discussion, and permits a greater degree of selection in applying theoretical consider ations.

Another broad group of theoretical problems arises from the interpretation of the transport properties of dense gases; these are of very considerable practical as well as theoretical interest. The outcome of many statistical-mechanical calculations which can be formulated with some mathematical rigour is much too complicated to be applied conveniently to experimental examples. For this reason the devising and testing of simpler models which permit some theoretical insight into transport processes in dense gases offers special opportunities for progress at the present time. In this direction, significant contributions to the discussion by Prof. H. C. Longuet. Higgins and J. P. Valleau (Cambridge), and by Dr. E. Whalley (National Research Council, Ottawa) were discussed by a number of contributors.

A third type of theoretical culculation at high pressures refers to properties of compressed gases, the variation of which with pressure can be attributed to attractive forces. Measurement of such properties as a function of pressure, and particularly a combination of several types of measurements, promises to give rewarding information about details of intermolecular attractions which it would be difficult to obtain in any other way. For example, a contribu. tion by Dr. J. A. Pople and Dr. R. A. Buckingham (Cambridge) indicates useful properties the dependence of which on pressure, though not extensively studied hitherto, should yield new information about molecular force-fields.

Though advances in techniques of working at high pressures were not, specifically included in this discus. sion, the increasing range of phenomena which can now be studied conveniently was illustrated by experimental studies such as those on the effects of pressure on the infra-red and electronic resonance spectra of gases, by Dr. 13. Vodar and his colleagues (Laboratoire de Haut Pressions, Bellevue). These promise to contribute novel features in our general knowledge of molecular force-fields. A. M. Benson and Prof. H. G. Drickamer (Illinois) made the interesting suggestion that the pressure coefficient of a vibrational frequency could be employed systomatically to supple- ment the actual numerical value of the frequency itself, in correlating spectral energy-levels with modes of vibration and thus with molecular structure.

The meeting also considered various aspects of chemical reactivity at high pressures. It is usual to separate the influence of pressure on the structure of the solvent, from its influence on various activation complexes involved in specific chemical reactions. From observed changes in the dielectric constant of methanol, discussed by Dr. S. D. Hamann and W. Strauss (Sydney), there appears to be a striking influence of pressure on the structure of this solvent. Prosumably this is connected with the open network structure of hydrogen bonds in liquid methanol. It would be interesting and important to know if such an influence of pressure on structure is observed generally in the case of hydrogen-bonded solvents. There was considerable discussion about, the interesting changes in the propertios of such solvents as they approach and traverse their critical points. For example, in water near and above its critical temperature, it may happer that some of the 'anomalous' properties associated with clusters of molecules of $\mathrm{H}_{2} \mathrm{O}$ with the tetrahedral ice arrangement are related in a sensitive way to the extension of such clusters in space.

So far as the activation complexes are concerned, relatively simple concepts, as discussed by various contributors, at present suffice to account for much of the observed influence of pressure on the free energy of activation. The influence of pressure on reactionrate is quite striking for certain fairly complex molecules, as in cases reported by Dr. S. D. Hamann and D. R. Toplitzky (Sydney), where a five-hundredfold increase in rate accompanies the increase in pressure up to 15,000 atm. On the other hand, expectations that the steric hindrance in specific reaction mechanisms might be reduced or even eliminated as a result of bond deformation at high pressures proved not to be fulfilled, at, any rate in the examples presented at this discussion by $\mathrm{K}$. F. Weale (Imperial College, London). Other striking influences of increases of pressure arise in polymerization reactions. For example, in the polvmerization of styrene, rates of propagation and of chain termination have been shown to depend in a marked way on the degree of compression of the solvent. In consequence the mean molecular weight is affected by pressure. Rather less seems to be known at present about how far chain-branching for a given size of macro-molecule is affected by the pressure at which it, has been formed. In the polymerization of ethylene discussed by various contributors, the reaction-rate likewise depends in a complex way on the pressure, owing to the various ways in which nearest neighbours influence chain-reactions as molecular packing becomes closer.

A group of investigations on physicochemical processes in detonation and shock waves was presented for discussion by various contributors. The systems studied differed widely in complexity. It seems clear that in heterogeneous polycrystalline mixtures, a complex diversity of phenomena can occur which is by no means fully elucidated. This applies, for example, to studies reported by Dr. L. Deffet and Boucart (Tir National, Brussels), by Dempster, and by Dr. W. Taylor (I.C.I., I.td., Nobel Division). The mixtures of explosive substances they described can only be termed 'solid' by convention; phenomena such as grain erosion in the detonation reaction-zone are of dominant importance and depend on the 
intercrystalline free space in a complex way. Much stimulating discussion was held about the physical chemistry of the reaction zone in detonations. The importance of the intercrystalline free space is further emphasized by a contribution which described the behaviour of single crystals studied individually. High initial pressures are found to have only a slight effect on the 'runaway temperature' in the self-heating of single crystals of explosives.

Experiments on the homogeneous detonation of acetylene should in principle be simpler to interpret than the behaviour of heterogeneous systems. However, the formation of solid products of detonation leads to complications when attempting theoretical interpretations. It is not clear at what stage the 'carbon' ultimately obtained from the detonation of acetylene is actually formed; it seems unlikely, furthermore, that the crystal structure and heat content of such 'carbon' can be taken as the same as in ideal graphite. The kinetics of pyrolysis of acetylene in shock waves to give carbon offers further information about reactions at transient high pressures, which present complications due to the formation of solid products of variable physical structure and chemical composition. Extensions of such kinetic studies promise to cover ranges of high pressure and high temperature not conveniently obtainable in other ways. The possibility of obtaining conveniently kinetic results at several hundred thousand atmospheres obviously attracts a number of research groups. However, as in other studies of transient phenomena, relaxation effects may complicate any interpretation of the results on the basis of the thermodynamies of high pressures. Detonation and shock velocities can now be measured with very considerable precision. The measurement of detonation and shock pressures still present technical difficulties, though they may become accessible from techniques such as X-ray shadowgraphy and measurements of mass flow. But in the case of detonations and shock waves there are very serious doubts about the applicability of 'temperature' at all as a significant modulus in describing the statistical distribution of various kinds of internal energy among the molecular and atomic species present. Active research in the physical chemistry of matter at high pressures receives still further stimulus from the possibility of observing transitions from insulator to conductor behaviour of various crystals when sufficiently compressed. Preliminary studies of this kind were described at the meeting and added further zest to a very lively twoday discussion.
A. R. UbBexohde

\section{OBITUARIES}

\section{Prof. J. C. Cruickshank}

John Cecrl Cruickshank, professor of bacteriology as applied to hygiene in the University of London at the London School of Hygiene and Tropical Medicine, died on October 30 at the age of fifty-seven. Educated at George Watson's College in Edinburgh, he served in the Gordon Highlanders at the end of the First World War, and then proceeded to the University of Edinburgh, whence he graduated M.B., Ch.B. in 1921. He took the D.T.M. at Liverpool in 1923, winning the Alan H. Milne Memorial Medal, and then served in the West African Medical Service in the Gambia for seven years, gaining tropical experience which was of great value to him and to his students later in London.

Cruickshank came to the London School of Hygiene and Tropical Medicine to take the diploma in bacteriology in 1933, and remained there first as demonstrator, then as lecturer in bacteriology. During the Second World War he directed Emergency Public Health Laboratory Services laboratories, first at Horsham, later at Exeter, returning to the School in 1945 as reader in bacteriology as applied to hygiene, to re-open the Department under the part-time direction of Prof. G. S. Wilson, and to start teaching courses again. Cruickshank was a great teacher, whose wide experience of tropical and public health bacteriology fitted him uniquely well to teach in courses for the diploma in bacteriology, the diploma in public health and the diploma in tropical medicine and hygiene. Many hundreds of students will remember his excellent teaching with gratitude. In 194.7 he became professor in bacteriology as applied to hygiene.

Throughout the past twenty-five years, Cruickshank had maintained a steady output of research on bacteriological topics, chiefly on brucella infections and on immunity. He acted for some years as expert adviser to the Public Health Laboratory Service on clostridia and on brucella. He served on the Water Pollution Research Board of the Department of Scientific and Industrial Research and its Detergents Committee, and on various other public committees and bodies. He was a member of the Pathological Society, the Society of General Microbiology, and the Medical Research Club. In 1952 he gained his M.D. (Edinburgh) with a gold medal. He was loved and respected by all his colleagues and students and all others who knew him; his early death is a great blow to the School. He leaves a widow, two sons and a daughter.

$$
\text { E. T. C. SPOONER }
$$

\section{Dr. John McLuckie}

DR. JOHN MCLUCKLE, until recently reader in botany in the University of Sydney, died on September 27 at the age of sixty-six. He was still in harness, for he was asked to come back after his official retirement to take the advanced mycology course. $\mathrm{He}$ had given a lecture and a practical class on the day of his death.

McLuckie was born in Killermont, in Dunbartonshire, on August 12, 1890. He was the eldest of a family of seven. His father was a gamekeeper, and as a boy John McLuckio learnt to handle a fishing rod and a gun-skills which he practised with great distinction during his forty years in Australia. From these early days he acquired, too, an intimate knowledge of natural history and a love for the countryside.

He won a bursary to the school which is now Bearsden Academy and proceeded in 1909 to the University of Glasgow, where he was a pupil of F. O. Bower. After graduation in 1914, McLuckie sailed for Australia to serve under Prof. A. A. Lawson (also one of Bower's pupils) in the newly established Botany Department in the University of Sydney. 